\title{
Reseña sobre Quinientos años de soledad: estudios sobre las desigualdades raciales en Brasil de Marcelo Paixão*
}

Rafael Antonio Diaz Diaz a

DOI: https://doi.org/10.11144/Javeriana.uh88.rqas

Pontificia Universidad Javeriana, Colombia

rdiaz@javeriana.edu.co

ORCID: http://orcid.org/0000-0002-8637-5967

Recibido: 20 Junio 2018

Aceptado: 05 Julio 2018

Publicado: 20 Diciembre 2019

Coincidiendo con el año (2016) en el que se dio inicio, a nivel global, el Decenio Internacional para los Afrodescendientes, se edita en y para Colombia esta colección de siete ensayos del reconocido intelectual afrobrasileño, economista y sociólogo Marcelo Paixão. Si bien no tan reconocido o visible en el ámbito de los estudios afrocolombianos, Paixão aborda en estos siete textos un conjunto de análisis, estudios, perspectivas y críticas pertinentes y relevantes que son insumo y referencia para la genealogía y el estado actual del corpus de los llamados estudios afrocolombianos. La otra razón de peso que justifica y hace importante la publicación de esta obra en nuestro medio radica en el hecho de que Brasil y Colombia representan los dos países latinoamericanos continentales con mayor porcentaje de población afrodescendiente, por lo que en esa medida también se precisa reconocer el avance o adelanto de los estudios afrobrasileños en varios campos disciplinares e interdisciplinares de las ciencias sociales y las humanidades respecto a los estudios afrocolombianos. En efecto, los estudios afrobrasileños se constituyen en referentes importantes e imprescindibles para el abordaje de los temas asociados a la población afrocolombiana, como el conjunto de ensayos reunidos y editados en este libro. Ello, en consecuencia, coloca en perspectiva la necesidad imperiosa y la importancia crucial de motivar o alentar los diálogos académicos y comunitarios entre Brasil y Colombia, al igual que la coyuntura o la motivación de abrir canales de intercomunicación entre Colombia y África, vía Brasil. Todo lo precedente explica el porqué de la edición académica de esta obra por parte de la antropóloga Claudia Mosquera Rosero-Labbé, investigadora del Departamento de Trabajo Social y del Centro de Estudios Sociales de la Universidad Nacional de Colombia, sede Bogotá.

El sugerente título de la obra, Quinientos años de soledad: estudios sobre las desigualdades raciales en Brasil, está inscrito desde su publicación y edición original en portugués en el 2013. Se hace explícitamente esta acotación puesto que, si bien los textos y análisis reunidos acá no cubren una temporalidad de quinientos años, el título en sí quiere, como lo señala Paixão, establecer un símil o un diálogo con el de la magna obra del nobel Gabriel García Márquez para indicar la experiencia secular y continental de las poblaciones de descendencia africana "de opresión y discriminación de los continentes históricamente marginados en todo el hemisferio" (38). En otros términos, el título, cruzado con los análisis contenidos en cada uno de los textos, apunta a señalar realidades transversales y sostenidas históricamente en cuanto a la experiencia histórica de los africanos desde el momento de su esclavización, su trágica y dolorosa conducción a las Américas, sus procesos de resistencia y su confrontación al desenvolvimiento de las sociedades esclavistas y raciales en las Américas. Las experiencias de opresión y discriminación con seguridad referencian históricamente la constitución de las desigualdades raciales, según reza el subtítulo de la obra, como esa dinámica transversal que aglutina los procesos subsecuentes que han marginado a estas poblaciones desde prácticas políticas de exclusión y retóricas racializadas de inferioridad. Este trasegar analítico desde el título mismo se cierra con una

Notas de autor

${ }^{a}$ Autor de correspondencia. Correo electrónico: rdiaz@javeriana.edu.co 
discusión provocadora, en el capítulo séptimo, y es nominar al racismo, en tanto agente de las desigualdades raciales en Brasil - históricamente constituido-, como un sistema de modernidad antropofágica, es decir, y de manera literal, como una máquina que devora seres humanos. Este punto de vista nos interesa de manera particular y sobresaliente toda vez que es críticamente relevante señalar que la modernidad occidental eurocéntrica se hizo posible a través del agenciamiento continental y luego global de la esclavización, posterior venta y expoliación de seres humanos a escalas numéricas progresivas hasta alcanzar varios millones de seres arrancados de sus territorios originales y posteriormente conducidos a distintas regiones de las Américas. Todo ello ha configurado lo que hemos venido denominando la modernidad esclavista hegemónica que, además, tuvo un pivote determinante como lo fue la constitución de los sistemas de dominación colonial o, en otras palabras, las modernidades coloniales.

Ahora bien, cuando se particulariza el perfil de cada uno de los siete artículos, podemos acercarnos, grosso modo, a los temas, las discusiones, los problemas, las tensiones y los abordajes desarrollados. Antes de entrar a señalar estas especificidades, cabe anotar que los siete textos pueden ser leídos sin algún orden lógico, ya que mantienen su particularidad, aunque evidentemente se aprecian argumentaciones y reflexiones análogas, similares y complementarias.

Estadística y raza son los principales protagonistas del primer estudio, eso sí en función de un campo políticamente sensible en los movimientos sociales y en las luchas identitarias de los pueblos afro como lo son los censos demográficos. Esta disección de demografía racial es notoriamente importante para el caso colombiano dado que tal procedimiento tiene una relación estrecha con la lucha y presión por hacer visibles los conglomerados poblacionales afros en el diseño y la ejecución de las políticas públicas que tienen que ver con las condiciones sociales de existencia de los pueblos afro.

Política, identidad y reconocimiento estadístico caracterizan la discusión desarrollada en el segundo capítulo o texto, siendo notoria acá una suerte de ejercicio analítico y comparativo, según las rondas censales efectuadas, para una muestra importante de países latinoamericanos y caribeños con presencia menor y mayoritaria de población afro en el conjunto total de la población nacional correspondiente. En la base de los resultados comparados se despliega un ejercicio fundamental y es cómo construir preguntas, mediciones e indicadores desde referentes políticos, identitarios y culturales que visibilicen el lugar de las comunidades afro en la construcción del Estado nación. No es, entonces, un ejercicio pura y llanamente cuantitativo o estadístico, sino ante todo de carácter político.

El abordaje de la tensión en el cruce de los indicadores de desarrollo humano (IDH) con el hecho palpable y actual de que la población afrobrasileña se encuentra en un estado de total exclusión es el objeto del tercer texto, que, en realidad, es la presentación argumentada y crítica de una investigación para el caso de Brasil. El estudio, hecho sobre la base de un análisis y de una exploración por regiones, particularizó, entre otros hallazgos, los niveles de exclusión en los que las mujeres afrodescendientes y sus congéneres blancas presentan los más bajos niveles de IDH. Regionalmente, el nordeste brasileño revela bajos índices de IDH en un conjunto de agrupaciones étnicas. En conjunto, la investigación termina por confrontar la realidad del racismo y del prejuicio racial frente al mito hegemónico de la democracia racial o a la retórica de la inevitable asimilación racial.

El cuarto capítulo se ubica en el periodo presidencia de Lula (2003-2010), enfocando las alteraciones y los cambios surtidos por sus políticas en lo que se refiere al "acceso al mercado del trabajo metropolitano brasileño” (224) por parte de la población afrobrasileña, tomando como variables determinantes el color y la raza. Al respecto y como se sabe, el gobierno de Lula fue, en términos de las políticas públicas, abiertamente favorable a las aspiraciones, realidades y necesidades de la inmensa población afrobrasileña, hasta el punto de nominar o caracterizar este periodo como el avance hacia un modelo que Paixão denomina un "crecimiento pro afrodescendiente". Analizando los alcances y los resultados, se estudia y se discriminan los factores que viabilizaron un aumento en las posibilidades del acceso al mercado laboral por parte de los trabajadores afrobrasileños, que pudieron atemperar o disminuir el ámbito de las desigualdades raciales. 
Del acceso al mercado laboral se transita, en el capítulo quinto, al peso que comportan las variables de raza y color en los indicadores de mortalidad materna en el subcontinente brasileño. Partiendo del hecho palpable de una alta incidencia de mortalidad materna entre las mujeres "prietas" o afros, se pone en cuestión la utilidad o conveniencia de identificar, en términos étnicos o de raza, las causas de mortalidad entre las madres. Sobre esta base idealmente se debería diseñar o proponer acciones estatales de política pública que contribuyan a la reducción de esas tasas de mortalidad, acción y reclamo que ha hecho de manera insistente la sociedad civil y que de muchas maneras han sido atendidas por la acción estatal.

Pasando a otro plano, en el capítulo sexto se examina uno de los temas más sensibles, política e ideológicamente, en el horizonte problemático de las poblaciones afro: las políticas de acción afirmativa que en sí pueden haber constituido uno de los aspectos que más ha generado discusión y polémica entre académicos, líderes afro y miembros de las comunidades de afrodescendientes en una escala de índole prácticamente global, pero particularmente latinoamericana. Precisamente, Paixão despliega acá una revisión crítica y un balance de siete matrices teóricas, como él mismo las llama, que se oponen o están en contravía a las políticas de acción afirmativa: marxista, genetista, liberal, funcionalista, democrático-racial, nacionalista y culturalista contemporánea. Obviamente, acá no hay espacio para adelantar un comentario al respecto, pero sí es preciso insistir en el hecho de que esta revisión crítica es bastante útil y constituye una excelente introducción al debate en torno a las políticas de acción afirmativa que, en todo caso, no es únicamente pertinente para el caso de Brasil; es más, es harto relevante para el caso africano que sufrió y padeció la esclavización y el dominio colonial. El ámbito de las acciones afirmativas, en conjunto, pone de relieve y en cuestión la utopía de una sociedad equitativa en el marco de la diferencia y la distinción, lo que supone superar el prejuicio racial, las desigualdades y las inequidades producidas por la blanquitud de la modernidad hegemónica.

Y, como ya lo habíamos insinuado al comienzo de esta reseña, en la presente edición de textos sobre las inequidades sociales y raciales en Brasil, Paixão retoma, en el séptimo y último capítulo, el concepto de antropofagia que, hace algunas décadas, propuso Oswald de Andrade en su reconocido texto Manifesto antropófago. El racismo, manifestación crucial y transversal de la modernidad y de la civilización occidental, es concebido literalmente como una máquina devoradora de seres humanos, frente a lo cual cabe referir, por un lado, la idea de Ana Arendt del fin de la humanidad con el racismo y, por el otro, el concepto de necropolitica del camerunés Achile Mbembe como aquello que define a la modernidad en tanto política de la muerte en vida y de la desaparición física. Es este marco el que le sirve a Paixão para adelantar un excelente análisis de deconstrucción de las interpretaciones, de cuño eurocéntrico, que terminaron por configurar un modelo basado en el argumento central de la inferioridad civilizatoria de los afrodescendientes, razón que justificaría la necesidad de "devorar", disolver y asimilar a los sujetos inferiores como garantía de viabilidad de la razón y el progreso en el territorio brasileño. En otros términos, el modelo asimilacionista se fundamenta en la retórica racista de que los afrodescendientes, en tanto seres originados en razas inferiores, se erigen en un obstáculo a la materialización del paradigma occidental. De igual manera, el confrontado marco explicativo del modelo de la asimilación en el marco de las relaciones raciales implica también tanto invisibilizar los rasgos y aportes de la cultura afrobrasileña, como evadir el hecho de las interacciones y los intercambios culturales entre las matrices de origen indígena, africana y lusitana, esto es, una especie de antropofagia transversal. Finalmente, se ofrece un valioso análisis comparativo y de contraste entre varios escenarios multirraciales como, por ejemplo, entre "el modelo brasileño de prejuicio" y el modelo norteamericano "basado en el origen" (380).

Por último, puede ser útil y funcional indicar que la suma de los siete textos produce un corpus bibliográfico representativo de las más diversas perspectivas y problemáticas que observan el ámbito de las genealogías, caracterizaciones, tensiones y discusiones alrededor de las desigualdades raciales en Brasil, posibilidad que es potenciada por la existencia, al final, de un índice temático.

\section{Licencia Creative Commons CC BY 4.0}

Cómo citar: Díaz Díaz, R. A. (2019). Reseña sobre Quinientos años de soledad: estudios sobre las desigualdades raciales en Brasil de Marcelo Paixão. Universitas Humanistica, (88), 1-6. https://doi.org/10.11144/Javeria na.uh88.rqas 